\title{
Regional convergence in Greece in the 1980s: an econometric investigation
}

\author{
LEO MICHELIS, ATHANASIOS P. PAPADOPOULOS* $\$$ and \\ GREGORY T. PAPANIKOS $\$$ \\ Department of Economics, Ryerson University, 350 Victoria Street, Toronto, Ontario, \\ Canada, M5B $2 \mathrm{~K} 3$ and $\$$ Department of Economics, University of Crete, Rethymno, \\ Crete, Greece GR 74100
}

The purpose of this paper is to evaluate empirically regional convergence in Greece during the 1981-1991 period of participation in the European Economic Community (EEC). Census data at NUTS III level of regional disaggregation are used. A number of structural policies undertaken in the 1980s, motivated by membership in the EEC, were conducive to regional convergence among the 51 NUTS III regions of Greece. Four different dependent variables and three model specifications are used to test the hypothesis of regional convergence. The overall evidence does not reject the idea of regional convergence. The estimated convergence coefficients are relatively similar across the three model specifications but they vary with the dependent variable used to measure convergence.

\section{INTRODUCTION}

The foundation of European integration is the development of lagging regions of the European Union (EU). The reduction of regional disparities has been on the main objective of the EU ever since its inception as the European Economic Community (EEC) in 1957. The Single European Act of 1987 explicitly aimed at reducing regional disparities by increasing regional spending. A recent report released by the Regional Policy Branch of the EU (see European Commission, 1995) reinstated its commitment to regional development. According to this report, the challenge for the $1990 \mathrm{~s}$ is to maintain the momentum for economic convergence and help the diverging regions to turn around. Sapir (1992) has evaluated the effects of European integration on trade, welfare and income distribution and concluded that they were beneficial. However, not all regions reaped the same benefits. Regional disparities within Europe were exacerbated and their analysis has received a lot of attention. In this study, the convergence process of 51 Greek regions between 1981 and 1991 is measured and evaluated.
Several empirical studies have used time series and crosssection data to measure and evaluate convergence among countries and regions. Baumol (1986) reported evidence in support of convergence among a subset of developed countries. When the sample was enlarged to include less developed countries convergence could not be confirmed. DeLong (1988) using a larger sample of industrialized countries has found divergence. Barro and Sala-i-Martin (1991) has found regional convergence among the US states during the 1880-1988 period and for a set of European regions during the 1950-1985 period. More recently, Sala-i-Martin (1996) reconfirmed the regional convergence hypothesis using regional data from the USA, Japan and a number of European Union member states.

A growing empirical literature deals with convergence within the European Union. Ben-David (1993), using country data, related trade liberalization to income convergence within the European Union. His results support the convergence hypothesis that poor regions tend to grow faster than rich ones. Neven and Gouyette (1995) reported that since 1975 there has been a process of convergence among

*Corresponding author. E-mail: appapa@econ.soc.uoc.gr 
107 EU regions. On the other hand, Bacchetta (1994) used data from 35 European regions and found no significant convergence. Cheshire and Carbonaro (1995) using different models and 122 urban EU regions reported mixed results depending upon the specification of the model.

There are two major limitations with the empirical studies just cited. First, most studies use data from North European regions (countries) and, second, the disaggregation of data is not sufficient enough to permit a more complete analysis of the convergence process. For example, in all studies Greek regions are excluded due to lack of data. In this paper, this gap is filled by investigating the convergence process in Greece during the period of 1981-1991 using the most disaggregated data available (NUTS III level of desegregation) for 51 regions. By concentrating on one country, we abstract from differences arising from macroeconomic policies and country specific characteristics. As Lucas (1988, p. 4) pointed out '... within-country income comparisons are easier to draw than across-country comparisons'.

The rest of the paper is organized as follows. Section II describes the regional policy context of the 1980s and presents several specific factors in support of the convergence hypothesis among the 51 Greek regions in the 1980s. Section III explains the concept of convergence and presents the various ways of measuring and modelling convergence. Section IV describes the data used and discusses some econometric issues related to the estimation of the convergence regression equations. Section $\mathrm{V}$ reports the econometric results and section VI concludes the paper.

\section{REGIONAL POLICY IN THE 1980s}

The decade of the 1980s was characterized by important structural changes in policy orientation in both Greece and the EU. In the EU three main events shaped the future policy setting. First the macroeconomics environment in the 1980s was characterized by stabilization policies to fight inflation at the expense of rising unemployment. Despite the improvement of the important macroeconomic indicators, the EU was lagging behind the major trading competitors, USA and Japan. This fact initiated the efforts for harmonization of the EU policies which led to the implementation of the Single European Act. Second, the enlargement of the community from nine to 12 member states in connection with the 'cohesion' concept described in the Single European Act gave a new dimension to the regional policy setting. This has been achieved by a series of new actions such as the Mediterranean Integrated Programmes. Third, the functioning of the European Monetary System adversely influenced the less prosperous regions of these countries.

On the other hand, during the same period Greece experienced a series of political and economics events which critically shaped the policy-making process. First, the entrance of Greece in the EEC as a full member facilitated the direction of Community funds towards the less prosperous regions of the country. Full membership in the EEC secured funds through the Common Agricultural Policy which contributed to the improvement of agricultural incomes. In addition, the European Regional Development Fund and to a lesser extent the European Social Fund have provided support for the less prosperous regions. Second, the implementation of the single European Act in 1987 set in motion policies which emphasized convergence across the borders of the European economies. The Structural Funds Support assisted in the implementation of numerous infrastructure programmes in the Greek regions while the Mediterranean Integrated Programmes favoured investment decisions undertaken mainly by the private sector. Third, all the economic decisions were taken in a relatively stable political environment with the government committed to income support of the wage earners and of the less developed regions of Greece. The improvement of the latter had been achieved through Community Funds in accord with the concept of cohesion of the Single European Act.

Most Greek regions have a high proportion of employment in the primary sectors of the economy. The agricultural labour force represents as much as $26 \%$ of total employment in Greece. Economic growth and industrial employment is concentrated into four regions, namely, Attica, Western Macedonia, Central Macedonia and Central Greece. The diffusion of growth to the rest of the country was limited, due to the lack of infrastructure, mainly in the transportation and communication sectors. The development of Attica fostered its urbanization but the decade of 1981-1991 revealed the cumulated problems of low productivity and high degree of labour force concentration in this region. This resulted in an increase in unemployment and a fall of the region's share in GDP from $42 \%$ in 1970 to $36 \%$ in 1985. Attica's drop in production favoured the other Greek regions, and light industries, food processing, clothing and leather products and tourism became the main source of employment creation. Central Macedonia, Central Greece, Thessalia and Crete gained the most.

The high degree of industry and employment concentration in Attica did not leave adequate profit margins for investment in this region and the low productivity in combination with a series of incentive laws gave the opportunity for initiatives to be undertaken by entrepreneurs and labour at a regional level. The central incentive that might have played an important role in this is Law 1268/82. According to this, Greece was divided into four greater regions. Incentives were given if investment was taking place in manufacturing, shipbuilding and repairing, new technology industries and tourism. The incentives had the form of subsidies, low interest payments by the public, 
increased depreciation and tax deductions for profits. Priority was given to the industries willing to relocate from the Attica region.

\section{MEASURING CONVERGENCE}

In this section several economic reasons are outlined for converging or diverging economies and state the measures of convergence that will be used in the empirical analysis below. Convergence of two or more economic series, such as per capita output in different regions, is said to occur if the difference between the series becomes arbitrarily small or tends to some constant as time elapses. For random series, stochastic convergence requires that the probability that the two series differ by a specified amount becomes arbitrarily small in the limit. If convergence fails to obtain we say that the series diverge.

Economic convergence is an important issue in growth theory and development economics. If growth rates in per capita output across different countries converge over time, then poor countries tend to develop faster than rich ones and catch-up with them eventually. This issue has given rise to the convergence hypothesis of whether poor regions or countries have the tendency to grow faster than rich ones (e.g. see Barro, 1991).

Economic theory is not entirely supportive of the convergence hypothesis. Whereas the standard neoclassical growth model predicts economic convergence, the more recent endogenous growth models reject convergence in general. In the neoclassical growth models of Solow (1956), Cass (1965) and Koopmans (1965), convergence is a natural outcome of exogenous technical change which migrates across countries with similar preferences and technology. Under the usual assumption of diminishing returns to reproducible capital, poor countries with low capitallabour ratios have high marginal products of capital and therefore tend to grow faster than rich countries with high capital-labour ratios. Moreover, free mobility of capital and labour across countries or regions will bid away differences in factor returns and thus factor incomes will converge to their steady-state values over time, at which point convergence ceases to be operational. Any observed differences in steady-state incomes should reflect region-specific characteristics such as differences in human capital, natural amenities or cost of living differences (see Levine and Renelt, 1992 and Sherwood-Call, 1996). Hence, the neoclassical growth model is consistent with strong economic convergence across different countries or regions.

In contrast, the new growth theories of endogenous models, pioneered primarily by the theoretical work of Romer (1986) and Lucas (1988), are less optimistic about economic convergence, and in general predict regional disparities or economic divergence. The new theories assume constant returns to scale with respect to a broad measure of capital that includes both physical and human capital which is accumulated through formal and informal education, training and experience. According to Romer, knowledge spillovers from one firm have positive effects on the production possibilities of other firms. These spillovers increase the return to human capital in regions with large amounts of physical capital. Lucas argues that the returns to skilled labour may be higher in regions with large concentration of skilled workers due to external economies of scale. In this situation skilled workers would migrate to regions with other skilled workers, thereby causing income in these regions to increase and diverge relative to income in other less developed regions. This result of economic divergence is quite different from the equalizing effect of labour migration on factor incomes in the standard neoclassical model. Economic divergence and regional disparities are also predicted in a different setting by Krugman (1991). In his model a developed region coexists with a less developed one in a pattern that depends on transportation costs and returns to scale.

It should be noted that the prediction of economic divergence in the endogenous growth theories is model-specific. Tamura's (1991) endogenous growth model produces per capita income convergence which is the result of human capital convergence. The latter is the outcome of knowledge spillovers to economic agents with different endowments of human capital. Knowledge spillovers cause below average human capital agents to grow faster than above average human capital agents, thereby causing human capital convergence which results in income convergence. For this reason, if the convergence hypothesis is tested and rejected by a given data set no clear conclusion can be drawn in favour of the new growth theories. Rather, the empirical evidence should be interpreted with caution in the particular context of the empirical work.

In this study, two well known measures of convergence are considered: $\sigma$-convergence and $\beta$-convergence. The concept of $\sigma$-convergence is concerned with the behaviour over time of the cross-sectional standard deviation of per capita output, income or some other relevant variable used to measure overall economic performance. Given a data set, if there is a decline in the cross-sectional standard deviation over time, then this is interpreted as evidence in support of convergence. This measure has been used by the European Commission in its reports of regional development in the EU.

The measure of $\beta$-convergence was suggested by Barro and Sala-i-Martin $(1991,1992)$ and derives as an approximation of the transitional dynamics of the standard neoclassical growth model. Briefly, following Barro and Sala-i-Martin (1992), the average growth rate of per capita output, $y$, in the time interval $(0, T)$, is given by the expression:

$$
(1 / T) \log \left[y_{T} / y_{0}\right]=\alpha-\left(1-\mathrm{e}^{-\beta T}\right)(1 / T) \log \left[y^{*} / y_{0}\right]
$$


where $\alpha$ is a constant and the positive parameter $\beta$ depends on the technology and preference parameters of the model and controls the speed of adjustment of $y$ to its steady state value $y^{*}$. The larger is $\beta$ the greater is the response of the average growth rate of $y$ to the gap between $y$ and $y^{*}$, that is the faster is the convergence to the steady state.

The model implies conditional convergence in the sense that what matters is $y_{0}$ relative to the steady state values of $\alpha$ and $y^{*}$ which may differ across regions. For this reason, in order to properly identify $\beta$ in empirical work, it is necessary to control for cross-sectional differences in steady state values. On the other hand, if cross-sectional differences can be reasonable ignored, then Equation 1 gives a form of unconditional $\beta$-convergence.

\section{DATA SOURCES AND ECONOMETRIC ISSUES}

The data set used in the empirical analysis is 1981 and 1991 census data for 51 regions of the Greek economy. The regions are specified according to the NUTS III level of desegregation. Four variables are constructed to measure convergence. The first is per capita GDP, most commonly used in studies of convergence. The second measure is per person employed GDP (e.g., Wolf, 1994). This variable is a proxy for the average productivity of labour. The third measure is per person employed taxable income by region respectively. This variable can be considered a proxy for a region's income since the available data does not allow for the construction of a disposable income variable. Finally, a measure of welfare is used which is an index based on per capita electricity consumption, number of automobiles, telephones and the number of per capita bank deposits. This index has been constructed by the Greek Centre for Planning and Economic Research. All data used in this study are reported by the National Statistical Service of Greece and the Bank of Greece.

Past empirical studies, e.g. Baumol (1986), have been criticized for sample selection bias in the sense that often only developed economies are analysed for convergence, e.g. DeLong (1988). If that is the case, the empirical findings would tend to favour the convergence hypothesis. The empirical analysis used here evades such a criticism since in the present study the sample is in effect the whole population. Moreover, the census data employed are the most reliable available in terms of measurement errors. Consequently, we are confident that the effects of errors in variables that tend to bias estimates of $\beta$ in Equation 1 are minimal. Also, since the data set is cross-sectional with, and heteroscedasticity could be a potential problem, White's (1980) method was used to obtain heteroscedasticity-robust covariance matrix estimates for the regression coefficients. The statistical results, however, were similar to those obtained by ordinary least squares.

\section{ANALYSIS OF EMPIRICAL RESULTS}

Table 1 reports the results of $\sigma$-convergence in all four variables that are used to measure the economic performance of a region. All four measures show that during the 1981-1991 period there has been $\sigma$-convergence among the 51 Greek regions. The estimated standard deviations of the logarithms of all the variables listed in Table 1 are uniformly lower in 1991 than in 1981. The greatest $\sigma$ convergence has occurred in per person taxable income, followed by the welfare index, per person employed GDP and per capita GDP. However, $\sigma$-convergence measures how the distribution of income evolves over time while $\beta$ convergence examines the mobility of income within the same distribution.

For the estimation of $\beta$-convergence, the following simplification of Equation 1, suggested by Barro and Sala-i-Martin, (1992) is used:

$$
\begin{aligned}
(1 / T) \log \left(y_{i t} / y_{i, t-1}\right)= & \alpha_{i}-\left(1-\mathrm{e}^{-\beta T}\right)(1 / T) \log \left(y_{i, t-1}\right) \\
& +u_{i, t} \quad i=1,2, \ldots, 51
\end{aligned}
$$

where $\alpha$ and $u$ are a constant and an error term respectively. The constant term depends on the steady-state values of $y$, the rate of technological progress and other variables that might be region specific. To capture these possible differences across Greek regions the following empirical specification suggested by Levine and Renelt (1992) will be estimated:

$$
y_{i, 02}=\gamma_{0}+\gamma_{1} y_{i, 0}+\gamma_{2} I_{i}+\gamma_{3} Z_{i}+u_{i} \quad i=1, \ldots, 51
$$

where:

$y_{i, 0 T}$ : is the average growth rate in region $i$ of the variable that measures economic performance over a specified period of time $(0, T)$; in the present case during the 1981-1991 period.

$y_{i, 0}$ : is the initial log value of $y$ of region $i$ in year 1981 .

$I_{i} \quad$ : is a vector of variables aimed at capturing the physical capital and human capital characteristics of region $i$.

Table 1. $\sigma$-Convergence

\begin{tabular}{lc}
\hline Variable & $\sigma$-value \\
\hline Log of per capita GDP 1981 & 0.1991 \\
Log of per capita GDP in 1991 & 0.1794 \\
Log of per person employed GDP in 1991 & 0.2178 \\
Log of per person employed GDP 1991 & 0.1748 \\
Log of per person employed taxable income in 1981 & 0.4509 \\
Log of per person employed taxable income in 1991 & 0.2909 \\
Log of welfare index 1981 & 0.2698 \\
Log of welfare index 1990 & 0.1894 \\
\hline
\end{tabular}


$Z_{i}$ : is another vector of variables that capture the peculiar characteristics of a region, other than human and physical capital.

In respect of the unknown coefficients, $\gamma_{0}$ is a regression constant, $\gamma_{1}=-\left(1-\mathrm{e}^{-\beta T}\right) / T$ is the regression coefficient incorporating the convergence coefficient $\beta$ and $\gamma_{2}$ and $\gamma_{3}$ are vector-valued coefficients associated with the regressors in $I$ and $Z$ respectively.

In this empirical study the set of $I$ variables includes population growth over the 1981-1991 period, per capita investment in 1981, the number of people with postsecondary education in 1981, the number of illiterate people in 1981 and the number of people with high school education in 1981. The list of $Z$ variables includes a number of variables such as the number of people unemployed, dummy variables to capture the investment regional policies as described in Section II, the area of each region, the amount of taxes paid by each region and a dummy variable for the regions that are islands. The effects of some of these variables that were economically and statistically significant are reported below.
Three empirical results for $\beta$-convergence are reported in Tables 2-6. First, a simple convergence model is estimated without the $I$ and $Z$ variables. Second, an $I$-model of convergence is estimated that adds all the $I$ variables to the simple model. Third a $Z$-model of convergence is estimated that extends the $I$-model by adding variables from the $Z$ list. The importance of this exercise lies in the robustness of the convergence coefficient $\beta$. If $\beta$ does not change its sign and remains statistically significant in all three models, then the conclusions are reinforced (see Levine and Renelt, 1992).

An overall finding that emerges from all model specifications is that during the 1981-1991 period the 51 Greek regions experienced $\beta$-convergence. There is mean reversion in growth rates in that the estimated $\gamma_{1}$ coefficient is negative and statistically significant across all the different model specifications. However, there are significant differences regarding the speed by which convergence has occurred depending on the variable used to measure economic performance.

In Table 2 the dependent variable is the growth rate of per capita output. The first column gives the regression

Table 2. Cross-region growth regressions. Dependent variable: the difference of the log of per capita GDP over the 1981-1991 period

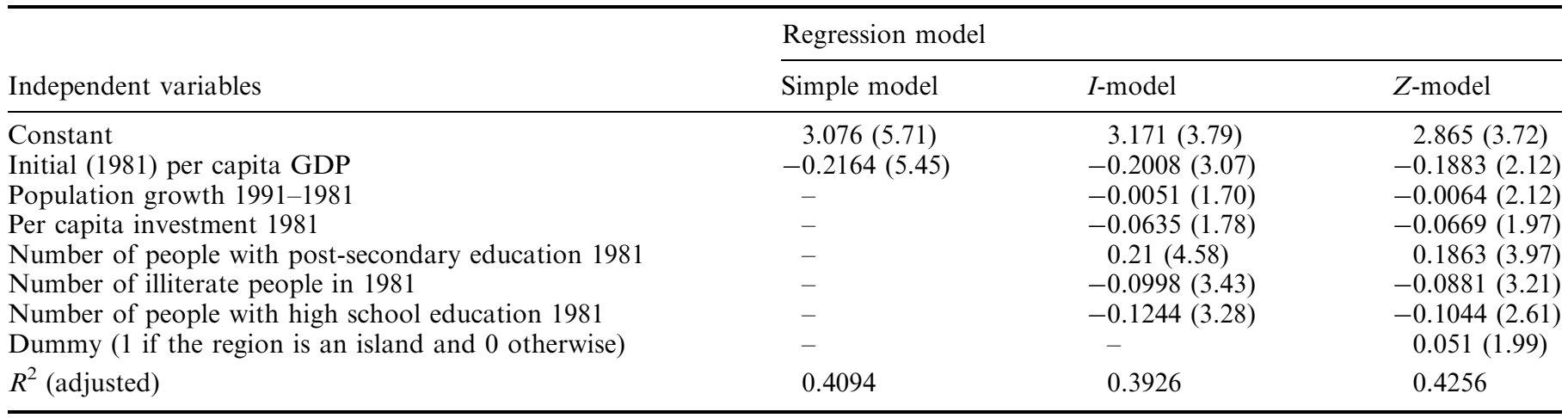

Note: The numbers in the parentheses are the absolute values of the $t$-statistics.

Table 3. Cross-region growth regressions. Dependent variable: the difference of the log of per person employed GDP over the 1981-1991 period

\begin{tabular}{|c|c|c|c|}
\hline Independent variables & \multicolumn{3}{|c|}{ Regression model } \\
\hline Constant & $5.616(5.86)$ & $5.499(3.94)$ & $5.268(3.56)$ \\
\hline Population growth 1991-1981 & - & $-0.0073(1.94)$ & $-0.0085(2.15)$ \\
\hline Per capita investment 1981 & - & $-0.0961(3.22)$ & $-0.10(2.66)$ \\
\hline Number of people with post-secondary education 1981 & - & $0.2087(2.22)$ & $0.1876(2.53)$ \\
\hline Dummy ( 1 if the region is an island and 0 otherwise) & - & - & $0.0449(1.36)$ \\
\hline$R^{2}$ (adjusted) & 0.3437 & 0.4563 & 0.4632 \\
\hline
\end{tabular}

Note: The numbers in the parentheses are the absolute values of the $t$-statistics. 
Table 4. Cross-region growth regressions. Dependent variable: the difference of the log of per person employed taxable income over the 1981-1991 period

\begin{tabular}{llll}
\hline & \multicolumn{2}{l}{ Regression model } & \\
\cline { 2 - 4 } Independent variables & Simple model & I-model & $10.99(7.8)$ \\
\hline Constant & $11.248(3.01)$ & $-0.8023(8.1)$ & $-0.0076(1.3)$ \\
Initial (1981) per person employed taxable income & $-0.8091(2.94)$ & $-0.0742(1.21)$ & $-0.8135(9.37)$ \\
Population growth 1991-1981 & - & $-0.5407(4.48)$ & $-0.123(2.43)$ \\
Per capita investment 1981 & - & $-0.344(3.88)$ & $-0.4043(3.87)$ \\
Number of people with post-secondary education 1981 & - & $-0.091(0.85)$ & $-0.0704(0.7)$ \\
Number of illiterate people in 1981 & - & - & $-0.1677(2.33)$ \\
Number of people with high school education 1981 & - & - & $0.2296(4.15)$ \\
Number of people unemployed 1981 & - & 0.8445 & 0.8729 \\
Dummy (1 if the region is an island and 0 otherwise) & 0.6254 & &
\end{tabular}

Note: The numbers in the parentheses are the absolute values of the $t$-statistics.

Table 5. Cross-region growth regressions. Dependent variable: the difference of the log of welfare over the 1981-1990 period

\begin{tabular}{|c|c|c|c|}
\hline Independent variables & \multicolumn{3}{|c|}{ Regression model } \\
\hline Constant & $2.367(8.81)$ & $2.476(5.46)$ & $2.61(6.50)$ \\
\hline Population growth 1991-1981 & - & $-0.0042(2.18)$ & $-0.0057(3.37)$ \\
\hline Per capita investment 1981 & - & $-0.0106(0.45)$ & $-0.0163(0.75)$ \\
\hline Number of people with post-secondary education 1981 & - & $0.0507(1.4)$ & $0.0062(0.17)$ \\
\hline Number of people unemployed 1981 & - & - & $-0.0961(3.78)$ \\
\hline Dummy ( 1 if the region is an island and 0 otherwise) & - & - & $0.0782(3.84)$ \\
\hline$R^{2}$ (adjusted) & 0.6415 & 0.6856 & 0.7531 \\
\hline
\end{tabular}

Note: The numbers in the parentheses are the absolute values of the $t$-statistics.

Table 6. Annual convergence rates (\%)

\begin{tabular}{lllc}
\hline Dependent variable & Simple model & I-model & $Z$-model \\
\hline Per capita GDP & 1.0 & 0.9 & 0.8 \\
Per person employed GDP & 1.8 & 1.7 & 1.6 \\
Per person employed taxable income & 6.5 & 6.4 & 6.6 \\
Welfare & 1.7 & 1.5 & 1.6 \\
\hline
\end{tabular}

results of the simple model for unconditional convergence. This specification includes only the initial level of the dependent variable. It excludes all variables that control for steady-state differences. The explanatory power of the regression is relatively high $(41 \%)$ and the convergence coefficient is negative and statistically significant.

The second column reports the regression results of the I-model. The independent variables are the number of people with post-secondary education, number of illiterate people and the number of people with high school education, initial per capita investment and population growth. The first three variables are included to capture the human capital differences that may exist among the 51 Greek regions. Per capita investment is used as a proxy for physical capital differences because capital stock data are not available. Population growth is statistically significant and it has the expected negative sign. However, the per capita investment has the opposite sign from what would be expected, but it is not statistically significant at the $5 \%$ level. The negative sign of high school graduates appears to be a puzzle. A similar result was obtained by Sherwood-Call (1996) for the states of the USA. One possible explanation may be the over-investment in high school education that may result from the fact that this level of education is required before the Greek students are permitted to write the entrance exams for 
post-secondary institutions. The other two human capital variables have the appropriate signs and are statistically significant. The number of post-secondary graduates has a positive impact on income output growth while the number of illiterate people has a negative impact. Compared to simple model, the inclusion of the additional regressors in the I-model causes the estimated convergence coefficient to fall, but not by much and it is still statistically significant.

The final column of Table 2 gives the regression results of the $Z$-model. The only statistically significant variable, from a range of variables that were used, is a dummy variable that controls for those regions that are islands. The estimated coefficient for the island dummy is positive and this is due to the fact that this dummy variable is a proxy for tourism's impact on Greece's regional economic growth. The results for the other $I$ variables are similar to the ones analysed above. The explanatory power of the regression increases, however, from $39.26 \%$ in the $I$-model to $42.56 \%$ in the $Z$-model. The convergence coefficient drops from 0.2164 in the simple model to 0.1883 in this model.

Table 3 reports the results when per person employed GDP is the dependent variable in Equation 3. This variable is used as a proxy for the average productivity of labour. The argument is that what is important for convergence is not the per capita output convergence but labour productivity convergence. Wolf (1994) argued that the results are biased in favour of convergence when per capita output is used instead of labour productivity. However, as the results in Table 3 show (the second row of the table), the estimates of $\gamma_{1}$ in the three estimated models are larger than those reported in Table 2, they have the correct sign and they are statistically significant. The explanatory power of the simple model is $34.37 \%$, but this increases to $45.63 \%$ in the $I$-model. The rest of the results are similar to those reported in Table 2.

Table 4 reports the regression results of the three models when taxable income is used as the dependent variable. Here, there are some differences that are worth reporting. First, the convergence is much larger in the $Z$-model. Second, the explanatory power of all three models is greatly improved compared to the results reported in Tables 2 and 3. The adjusted $R^{2}$ are now $62.54 \%$ in the simple model, $84.45 \%$ in the $I$-model and $87.29 \%$ in the $Z$-model. Third, the high school variable has a negative coefficient still, but it is not statistically significant. Fourth, the $Z$-model now includes a dummy variable for the islands as well as the number of people unemployed in $1981 \mathrm{in}$ each region. These two variables have the expected impact on growth of taxable income respectively, and are statistically significant.

Table 5 reports the regression results when welfare growth is used as the dependent variable for the three models. Because of data limitations welfare convergence is examined for the period 1981-1990. The estimated coefficient for initial 1981 welfare is negative and strongly significant in all three model specifications, implying convergence of welfare rates across the 51 Greek regions. Since the welfare index is constructed from items consumed by the typical household, the empirical results confirm the fact that consumption patterns became more homogeneous across all parts of Greece in the 1980s. From the other variables, only population growth is statistically significant in the $I$-model. The physical and human capital variables are statistically insignificant. To a large extent this is not surprising, since welfare depends primarily on the patterns consumption and income which, in general, are not highly correlated with educational attainment and the level of gross investment. On the other hand, the channelling of EU funds to less prosperous regions of Greece in the 1980s contributed positively to raising welfare standards in these regions. Another finding from this table is that only population growth and the initial level of welfare are statistically significant in the $I$-model. For the $Z$-model the results are similar with ones reported in Table 5. However, a number of $I$-variables are not statistically significant.

The idea of $\beta$-convergence is to measure the speed by which the poor regions are catching up with the rich regions. From the estimated convergence coefficients of Tables $2-5$, the $\beta$ coefficient can be computed using the relation $\gamma_{1}=-\left(1-\mathrm{e}^{-\beta T}\right) / T$. For the four dependent variables and the three different models, the annual rate of convergence was calculated. The results are reported in Table 6. According to Sala-i-Martin (1996) the convergence process is surprisingly similar across data sets so much so that '.. economies converge at a speed of about two percent per year'. Since most studies use per capita GDP, the present results indicate that Greek regions were lagging behind in the convergence process since they were actually converging at less than $1 \%$ per year. The same figure is higher but still less than $2 \%$ when the per person employed GDP and welfare are used as the dependent variables. When taxable income is used, then the speed of convergence increases dramatically but the results should be interpreted with caution because for a number of professional people (lawyers, doctors, accountants, merchants) the government uses 'objective' criteria to determine taxable income. Since these tax laws were implemented in the 1980s, it is not surprising that high convergence in taxable income is obtained. Actually, in this case there is convergence of income reported for tax purposes. This can be considered as convergence of tax evasion which is widespread in Greece.

\section{CONCLUSION}

This paper empirically evaluated regional convergence among 51 Greek regions during the 1980s, the first decade 
of Greece's integration with the European Economic Community. Two measures of convergence were used: $\sigma$-convergence and $\beta$-convergence. Four different dependent variables were used against which the convergence hypothesis was tested: per capita GDP, per person employed GDP, per capita taxable income, and an index of the regions' welfare. For each dependent variable three model specifications were used: a simple model, a conditional model that uses human and physical capital variables as independent variables (I-model) and a $Z$-model that uses in addition to previous variables other region-specific and dummy variables.

All the empirical results support the hypothesis of regional convergence. However, the speed by which convergence occurs is below the $2 \%$ threshold reported by Sala-i-Martin (1996). Another important empirical result is that the $\beta$-convergence is similar across models and dependent variables with the only difference for the taxable income variable.

\section{ACKNOWLEDGEMENTS}

This paper was partly financed by the Greek General Secretary of Research and Technology, Ministry of Development. The first author is grateful for financial support from a SSHRC Canada grant. All remaining errors are ours.

\section{REFERENCES}

Bacchetta, P. (1994) Regional investment and growth in the European community, Mimeo, IAE, Barcelona.

Barro, R. J. (1991) Economic growth in the cross section of countries, The Quarterly Journal of Economics, CVI, 407-43.

Barro, R. J. and Sala-i-Martin, X. (1991) Convergence across states and regions, Brookings Papers on Economic Activity, 1, 107-58.

Barro, R. J. and Sala-i-Martin, X. (1992) Convergence, Journal of Political Economy, 100, 223-51.

Baumol, W. J. (1986) Productivity growth, convergence, and welfare: what the long-run data show, American Economic Review, 76, 1072.
Ben-David, D. (1993) Equalizing exchange: trade liberalization and income convergence, The Quarterly Journal of Economics, CVIII, 652-79.

Cass, D. (1965) Optimum growth in an aggregative model of capital accumulation, Review of Economic Studies, 32, 233-40.

Cheshire, P. and Carbonaro, G. (1995) Convergence/divergence in regional growth rates: an empty black box?, in Convergence and Divergence Among European Regions (Eds) R. A. Vickerman and H. W. Armstrong, European Research in Regional Science, Pion, London, pp. 89-111.

DeLong, B. (1988) Productivity growth, convergence, and welfare: comment, American Economic Review, 78, 1138-54.

European Commission (1995) Cohesion and the Development Challenge Facing the Lagging Regions, European Commission, Regional Development Studies, Luxembourg.

Koopmans, T. C. (1965) On the concept of optimal economic growth, in The Econometric Approach to Development Planning, North Holland, Amsterdam, pp. 225-87.

Krugman, P. (1991) Increasing returns and economic geography, Journal of Political Economy, 99, 483-99.

Levine, R. and Renelt, D. (1992) A sensitivity analysis of crosscountry growth regressions, American Economic Review, 82, 942-63.

Lucas, R. E. Jr. (1988) On the mechanics of economic development, Journal of Monetary Economics, 22, 3-42.

Neven, D. and Gouyette, C. (1995) Regional convergence in the European Community, Journal of Common Market Studies, 33, 47-65.

Romer, P. M. (1986) Increasing returns and long-run growth, Journal of Political Economy, 94, 1002-37.

Sali-i-Martin, X. (1996) Regional cohesion: evidence and theories of regional growth and convergence, European Economic Review, 40, 1325-52.

Sapir, A. (1992) Regional integration in Europe, The Economic Journal, 102, 1491-506.

Sherwood-Call, C. (1996) The 1980's divergence in state per capita incomes: what does it tell us?, Federal Reserve Bank of San Francisco Economic Review, 1, 14-25.

Solow, R. M. (1956) A contribution to the theory of economic growth, Quarterly Journal of Economics, 70, 65-94.

Tamura, R. (1991) Income convergence in an endogenous growth model, Journal of Political Economy, 99, 522-40.

Wolf, H. C. (1994) Growth convergence reconsidered, Weltwirtschaftliches Archiv, 130, 747-59.

White, H. (1980) A heteroskedasticity consistent covariance matrix estimator and a direct test of heteroskedasticity, Econometrica, 48, 817-38. 